\title{
Kv7/M-type potassium channels in rat skin keratinocytes
}

\author{
Joanne M. Reilly • Vsevolod Telezhkin • \\ Gayle M. Passmore • Stephen J. Marsh • David A. Brown
}

Received: 21 February 2013 /Revised: 19 March 2013 / Accepted: 22 March 2013 / Published online: 17 April 2013

(C) The Author(s) 2013. This article is published with open access at Springerlink.com

\begin{abstract}
Skin keratinocytes fulfil important signalling and protective functions. Immunocytochemical experiments revealed the unexpected presence of immunoreactivity for the M-type potassium channel subunit Kv7.2 in the keratinocyte layer of intact rat paw skin and in keratinocytes isolated from the skin of 1-day-old rats and cultured in vitro for 310 days. Application of the M-channel enhancer retigabine $(3-10 \mu \mathrm{M})$ to isolated cultured rat keratinocytes: (a) increased outward membrane currents recorded under voltage clamp, (b) produced $\sim 3 \mathrm{mV}$ hyperpolarization at rest, (c) enhanced $\sim 3$-fold the release of ATP induced by the TRPV3 agonist carvacrol (1 $\mathrm{mM})$ and (d) increased the amplitude of the carvacrol-induced intracellular $\mathrm{Ca}^{2+}$ transient measured with Fura-2. The effect of retigabine on ATP release was prevented by the M-channel blocking agent XE991. We conclude that rat skin keratinocytes possess M-channels that, when activated, can modify their physiological properties, with potential significance for their sensory and other biological functions.
\end{abstract}

Keywords Potassium channels $\cdot$ Keratinocytes $\cdot$ ATP release $\cdot$ Immunocytochemistry $\cdot$ Membrane currents $\cdot$ Calcium

Electronic supplementary material The online version of this article (doi:10.1007/s00424-013-1276-2) contains supplementary material, which is available to authorized users.

J. M. Reilly • V. Telezhkin • G. M. Passmore · S. J. Marsh •

D. A. Brown $(\square)$

Department of Neuroscience, Physiology and Pharmacology,

University College London, Gower Street,

London WC1E 6BT, UK

e-mail: d.a.brown@ucl.ac.uk

Present Address:

V. Telezhkin

Cardiff School of Biosciences, The Sir Martin Evans Building,

Museum Avenue,

Cardiff CF10 3AX, UK

\section{Introduction}

Skin keratinocytes express several types of ion channel, which are variably involved in the secretion of signalling molecules, keratinocyte differentiation and the regulation of skin impermeability. These include voltage-gated $\mathrm{Na}^{+}$channels [48]; epithelial $\mathrm{ENaC}(S C N N 1) \mathrm{Na}^{+}$channels [7]; L-type $(\alpha 1 \mathrm{C})$ voltage-gated $\mathrm{Ca}^{2+}$ channels [11]; a large-conductance, $\mathrm{Ca}^{2+}$ independent $\mathrm{K}^{+}$channel [19]; large, intermediate and small conductance $\mathrm{Ca}^{2+}$-activated $\mathrm{K}^{+}$channels (BKCa [19, 40], hIK1 [22], hSK4 [21]); Kir6.1, Kir6.2 and SUR ATP-gated inward rectifier $\mathrm{K}^{+}$channel subunits [8]; several twin-pore $\mathrm{K}^{+}$ channels, principally TREK-1, TREK-2 and TRAAK [20] and several transient receptor potential (TRP) cation channels [25], including TRPV1 [18], TRPV3 [35] and TRPV4 [29], TRPA1 $[1,4]$ and several TRPC channels $[3,16]$.

In the course of a recent study on the location and function of M-type $\mathrm{Kv} 7 \mathrm{~K}^{+}$channels in nociceptive sensory fibre terminals in the hairy skin of the rat paw [34], we noted that immunoreactivity for the Kv7.2 subunit was not restricted to the nerve fibres but could also be detected in the inner layer of the epidermis (J. Reilly, unpublished). In the present paper, we show that this results from its expression in skin keratinocytes and that these channels, which are normally associated with neurons, can play a functional role in modulating the stimulated release of ATP from the keratinocytes.

\section{Methods}

Keratinocyte preparation and culture

Primary epidermal keratinocytes were cultured according to the methods described by Dlugosz et al [15]. One-day-old rats were killed in accordance with schedule 1 of the UK Animals (Scientific Procedures) Act 1986. The skin from the back and abdomen was removed and sequentially 
washed for $2 \mathrm{~min}$ in $0.01 \mathrm{M}$ phosphate-buffered saline (PBS; Sigma UK)/1 \% antibiotic-antimycotic (100×) liquid (Invitrogen, UK), $70 \%$ ethanol and 0.01 M PBS (Sigma UK) $/ 1 \%$ antibiotic-antimycotic $(100 \times)$ liquid (Invitrogen, UK). The subcutaneous fat was removed by gently scraping. The skin was floated dermis side down in trypsin $0.25 \%$ EDTA solution (Invitrogen, UK) overnight at $4{ }^{\circ} \mathrm{C}$. The following day residual dermal tissue was removed by gently scraping. The epidermis was sliced into sections, placed into keratinocyte serum-free media (keratinocyte SFM) (Invitrogen, UK) supplemented with $10 \%$ foetal bovine serum (Invitrogen, UK) and $1 \%$ antibiotic-antimycotic $(100 \times)$ liquid (Invitrogen, UK) and stirred for $30 \mathrm{~min}$ at room temperature. The keratinocyte suspension was passed through a nylon mesh cell strainer $(70 \mu \mathrm{m}$; BD Falcon, USA) and the keratinocytes harvested by centrifugation at $168 \times g$ for $5 \mathrm{~min}$. The resultant cell pellet was re-suspended in keratinocyte SFM supplemented with $1 \%$ antibioticantimycotic $(100 \times)$ liquid and plated equally onto Petri dishes or glass coverslips. The medium was replaced after $15 \mathrm{~h}$ with keratinocyte growth SFM and every $48 \mathrm{~h}$ subsequently. Keratinocytes were maintained for up to 3 weeks or until confluence was reached. Older rats (up to P7) gave much poorer yields of confluent keratinocytes.

\section{Immunohistochemistry}

Intact skin Sprague-Dawley rats $(\sim 150 \mathrm{~g})$ were deeply anaesthetised with ketamine/xylazine hydrochloride solution $(1 \mathrm{ml} / \mathrm{kg}$, i.p., Sigma, UK) in accordance with schedule 1 of the Animals (Scientific Procedures) Act 1986 and transcardially perfused with ice-cold heparinised saline (9\% $w / v \mathrm{NaCl}$ (VWR, UK), 50,000 U/1 heparin (Sigma, UK)) and then $4 \%$ paraformaldehyde (EMS Diasum, USA) in PBS (Sigma, UK). The skin from either the hairy dorsal or plantar surface of the hind paw was removed, post-fixed for $3 \mathrm{~h}$ with $4 \%$ paraformaldehyde in PBS, rinsed with PBS and then cryo-protected via immersion overnight in a $30 \%$ sucrose (VWR, UK)/ $0.01 \% \mathrm{Na}$ azide (Sigma, UK)/PBS solution. Cryosections $(40 \mu \mathrm{m})$ were obtained using a freezing microtome (Leica Microsystems, Germany) and free floating sections placed into PBS. Sections were incubated with blocking solution (PBS containing $3 \%$ goat serum and $3 \%$ Triton ${ }^{\circledR}$ X-100 (Sigma, UK)) followed by incubation overnight at $4{ }^{\circ} \mathrm{C}$ with primary antibody (see below). The sections were rinsed then incubated with a fluorophoreconjugated secondary antibody (Invitrogen, UK) for monoclonal antibodies, or a biotinylated secondary antibody (Sigma, UK) then with Cy3-conjugated streptavidin (Sigma, UK) for detecting polyclonal antibodies.

Cultured keratinocytes Cultured cells on cover slips were washed twice with $0.01 \mathrm{M}$ PBS and then fixed in $4 \%$ paraformaldehyde in PBS for $15 \mathrm{~min}$. After fixation, the cells were washed $(3 \times)$ for $10 \mathrm{~min}$ and then incubated for $1 \mathrm{~h}$ at room temperature with the above blocking solution or one containing $1 \%(w / v)$ bovine serum albumin, plus $0.3 \%$ $(v / v)$ Triton X-100 ${ }^{\mathrm{TM}}$ or $0.3 \%$ TWEEN ${ }^{\circledR} 20$ (Sigma, UK). Cells were incubated overnight at $4{ }^{\circ} \mathrm{C}$ with the primary antibodies then treated with secondary antibodies or biotinstreptavidin as described above for tissue sections.

Staining of skin sections and cultured keratinocytes was visualised using a Leica CA TCS SP2 AOBS spectral confocal microscope (Leica, Germany). The gain, exposure time and wavelength were optimised for the excitation and emission spectra of each fluorophore. Control experiments performed without primary antibodies did not show labelling above background.

Antibodies The following primary antibodies, with final dilutions, were used: Alomone Kv7.2 rabbit polyclonal against rat Kv7.2 (epitope residues 578-593), $0.7 \mu \mathrm{g} / \mathrm{ml}$ (Alomone, Israel); Abcam Kv7.2 rabbit polyclonal against human Kv7.2 (epitope residues 850-end of C-terminus), $3 \mu \mathrm{g} / \mathrm{ml}$ (Abcam, Cambridge, UK) and Neuromab mouse Kv7.2 monoclonal against human Kv7.2 (1-50), 1:100 (Neuromab, Davis, CA, USA). The following secondary antibodies were used: biotinylated goat anti-rabbit (Vector Laboratories, UK), 1:333; biotinylated goat anti-mouse (Vector Laboratories, UK) goat anti-mouse rhodamine (Invitrogen, UK), 1:100 and goat anti-rabbit Rhodamine

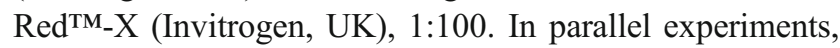
the antibodies were tested in cultured rat sympathetic neurons [17]; in these, the specificity of the antibodies for the Kv7.2 protein was verified by adding a 10 -fold excess of the appropriate epitope (where available) $1 \mathrm{~h}$ before adding the primary antibody (Supplementary Fig. S1). To assess secondary antibody specificity, in each keratinocyte experimental set a control was included in which the primary antibody was omitted.

\section{Electrophysiology}

Macroscopic currents and membrane potentials in isolated cultured keratinocytes were recorded using the voltage clamp perforated-patch technique as described in [38, 43]. The bath solution was $N$-2-hydroxyethylpiperazine- $N N^{\prime}-2$ ethanesulfonic acid (HEPES)-buffered Krebs' solution containing (in millimolar): $144 \mathrm{NaCl}, 2.5 \mathrm{KCl}, 0.5 \mathrm{MgCl}_{2}$, $2 \mathrm{CaCl}_{2}, 10$ D-glucose and 5 HEPES; $\mathrm{pH}$ was adjusted to 7.4 using Trizma base. The pipette solution contained (in millimolars): $30 \mathrm{KCl}, 80 \mathrm{~K}$-acetate, 40 HEPES, $3 \mathrm{MgCl}_{2}, 1$ $\mathrm{CaCl}_{2}$ and 3 ethylene glycol tetraacetic acid; free $\left[\mathrm{Ca}^{2+}\right]_{i}$ was adjusted to $100 \mathrm{nM}$; $\mathrm{pH}$ was adjusted to 7.2 with $\mathrm{KOH}$. Amphotericin B $300 \mu \mathrm{g} / \mu \mathrm{l}$ was used as a perforating agent. Pipette resistances were 5-10 $\mathrm{M} \Omega$ when filled with the 
pipette solution. Seal resistances were $>1 \mathrm{G} \Omega$. Series resistance was compensated $60-90 \%$. The mean capacitance of the cells studied was $15.6 \pm 1.9 \mathrm{pF}(n=9)$. All experiments were performed at a controlled room temperature (22 \pm $0.5^{\circ} \mathrm{C}$ ). All recordings were made using an Axopatch 200A amplifier and Digidata 1440 A/D interface (Axon Instruments, Forster City, CA, USA) and with a pipette holder optimized for low noise recordings (G23 Instruments, UCL). All recordings were filtered with an eightpole Bessel filter at $5 \mathrm{kHz}$ and digitized at $10 \mathrm{kHz}$. For recording macroscopic currents in perforated-patch configuration, cells were held at $-60 \mathrm{mV}$ and commanded to voltages from -100 to $+50 \mathrm{mV}$ in ramps of $25 \mathrm{~s}$ duration.

\section{ATP release}

ATP release from the keratinocytes was measured using a modification of the standard luciferase reaction [30]. Keratinocytes were cultured until they reached confluence (1-3 weeks). The keratinocyte growth SFM was replaced with HEPES-buffered Krebs solution (composition as for electrophysiological experiments) and incubated for $1 \mathrm{~h}$ at room temperature $\left(\sim 21-25^{\circ} \mathrm{C}\right)$ so that any ATP released due to mechanical disruption or temperature change would be metabolised. Drugs were applied for $10 \mathrm{~min}$. An equivalent volume of HEPES-buffered Krebs was added to control dishes to control for experimental errors resulting from possible mechanical disturbance to the keratinocytes

ATP release was determined by adding a $50-\mu l$ sample of supernatant to an equal volume of CellTiter-Glo ${ }^{\circledR}$ Reagent (Promega, USA). This was vortexed and equilibrated at room temperature for $10 \mathrm{~min}$. The sample was transferred to a disposable cuvette $(8 \times 50 \mathrm{~mm})$, and light emission was measured in a luminometer (Model 20E, Promega, USA). A standard curve was constructed using known concentrations of ATP. The luminometer reading was linearly related to the ATP concentration over the range 0 to $3 \mu \mathrm{M}$, with a slope of $1.56 \mathrm{U}$ output $/ \mathrm{nM}$ (ATP). This was used to convert luminometer reading to concentration of ATP in $50 \mu 1$ keratinocyte supernatant. We did not convert concentrations to amounts released since we do not know what fraction of released ATP might or might not have been metabolized and whether this was a constant fraction or not.

\section{Calcium imaging}

Intracellular free $\mathrm{Ca}^{2+}$ was monitored using the cell permeable acetoxymethyl (AM) ester of Fura-2 (Fura-2 AM, Invitrogen, $\mathrm{UK})$. The keratinocytes were incubated for $1 \mathrm{~h}$ at room temperature $\left(22-25^{\circ} \mathrm{C}\right)$ with $5 \mu \mathrm{M}$ Fura-2 AM (final concentration) dissolved in DMSO with $10 \%$ pluronic acid (Invitrogen, UK) and then perfused for 20 min prior to recording with HEPES buffered Krebs containing $0.1 \%(w / v)$ sulfinpyrazone (to minimize loss of Fura-2; Sigma, UK). Cells were visualised on a Nikon Diaphot 300 inverted phase contrast microscope using an oil immersion $\times 40$ fluorescent objective (Nikon Instruments, USA). Cells were excited at 350 and $380 \mathrm{~nm}$ from a xenon short arc lamp (XBO; Osram, UK) within a Polychrome II monochromator (TILL Photonics, Germany), controlled by Openlab 3.1 Image acquisition software (Improvision, UK) on an Apple Mac G4 computer. Excitation light intensity was regulated using quartz neutral density filters to reduce photo-bleaching of the fluorescent probe. Emitted light was passed via a dichroic mirror $(400 \mathrm{~nm})$ through a bandpass filter $(520 \pm 20 \mathrm{~nm})$ before being redirected to a 12-bit greyscale Hamamatsu C4880-80 camera (Hamamatsu, Japan). A Hamamastu CCD camera controller enabled the control of exposure times and facilitated image capture. Suitable pseudo-colour palettes were overlaid onto the images to enhance visualisation. To minimise photo bleaching, experiments were performed in a dark room, and exposure times were kept to a minimum. Images acquired at 350 and $380 \mathrm{~nm}$ excitations were subjected to a ratiometric algorithm undertaken following background light subtraction at each excitation wavelength. For each cell, an area of cytoplasm was selected from which the changes in mean 350:380 ratio with time were plotted as a two-dimensional graph.

\section{Results}

Immunohistochemistry

Intact skin Intact hairy skin from the dorsal rat paw showed strong immunoreactive staining for Kv7.2 within the epidermal layer (Fig. 1 a) and around the hair follicles (Fig. 1 b). In plantar paw skin staining of Kv7.2 was apparent in the layers adjacent to the dermal-epidermal border, in the stratum germinativum and stratum spinosum (Fig. 2 a). Here, staining of individual keratinocytes could be clearly seen (Fig. 2 b). No staining was observed when the primary antibody was omitted (Fig. 2 c). Kv7.2 staining density in single keratinocytes was comparable to that in neighbouring peripheral nerve fibres (Supplementary Fig. S2).

Cultured keratinocytes Kv7.2 immunoreactivity was also observed in isolated keratinocytes cultured from the back skin of 1-day-old rats. Figure 3 shows immunoreactivity detected with two different antibodies, a polyclonal antibody (Abcam) and a monoclonal antibody (Neutromab). Immunoreactivity increased to a maximum after 5 days in culture (rows b and c). No immunoreactivity was observed in the absence of a primary antibody (row d). The transmitted light images of the keratinocytes (columns 2 and 4) showed similar morphology to those cultured to similar densities in other studies [24]. 


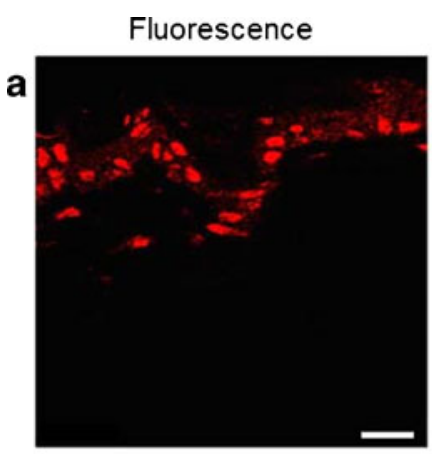

Transmitted light image

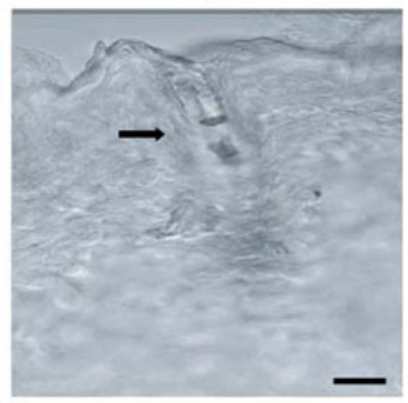

b
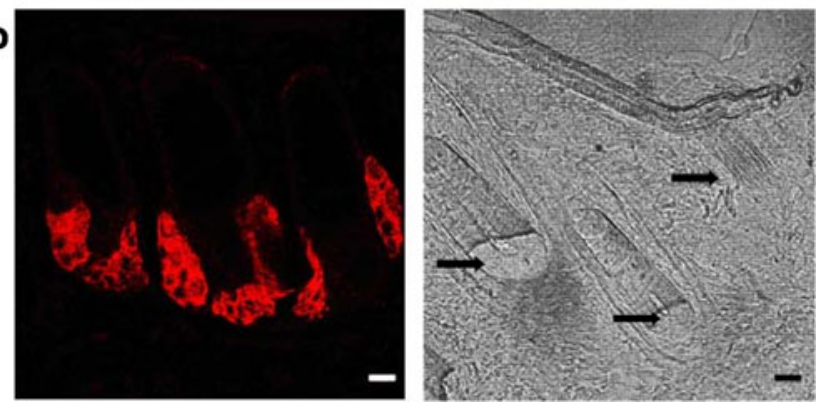

Fig. 1 Kv7.2 antibody staining within keratinocytes in intact rat skin. Left side images fluorescence; right side transmitted light images. a Keratinocytes immunoreactive to Kv7.2 (Alomone) within the outer epidermal layer. $b$ Keratinocytes immunoreactive to Kv7.2 (Abcam) within the epidermal layer surrounding the hair follicle. The arrows in the transmitted light images point to hair follicles. Scale bar $40 \mu \mathrm{m}$

\section{Membrane currents}

Kv7.2 protein is a subunit of the M-channel [17, 44], a lowthreshold, non-inactivating voltage-gated $\mathrm{K}^{+}$channel [10]. To test for the presence of an M-current in keratinocytes, we recorded membrane currents under perforated-patch conditions from isolated cultured cells which had first been trypsinized then replated to minimize electrical coupling (see "Methods"). The experimental protocol we adopted is shown in Fig. 4a. We applied voltage ramps from -100 to $+50 \mathrm{mV}$ at two different speeds, fast (500 ms) and slow (25 s). With the fast ramp, an initial inward current appeared between -40 and $-10 \mathrm{mV}$, followed by a large outward current (Fig. 4b). Using the slow ramp, the initial inward current was replaced by an outward current 'hump', followed by a more sustained outward current but of much reduced amplitude. This indicates a substantial inactivating component of the outward current, as shown by the response to the 3-s voltage step in Fig. 4a. The inward current and much of the outward current (including most of the 'hump' current) was inhibited by $100 \mu \mathrm{M} \mathrm{La}^{3+}$ (Fig. 4b2). This suggests that (a) the inward current was carried by a $\mathrm{Ca}^{2+}$-permeable cation channel such as a TRPV channel [32] (see "Introduction" and below) and (b) the 'hump' current and much of the current activated at more positive potentials was generated by $\mathrm{Ca}^{2+}$-activated $\mathrm{K}^{+}$channels $[21,27,28]$, with a possible contribution of $\mathrm{Ca}^{2+}$-activated $\mathrm{Cl}^{-}$channels [21] (since $E_{\mathrm{Cl}}$ was around $-35 \mathrm{mV}$ ).
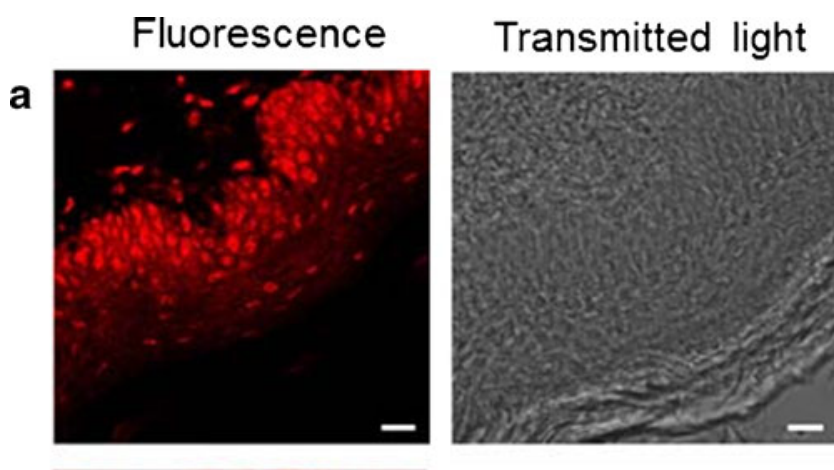

b
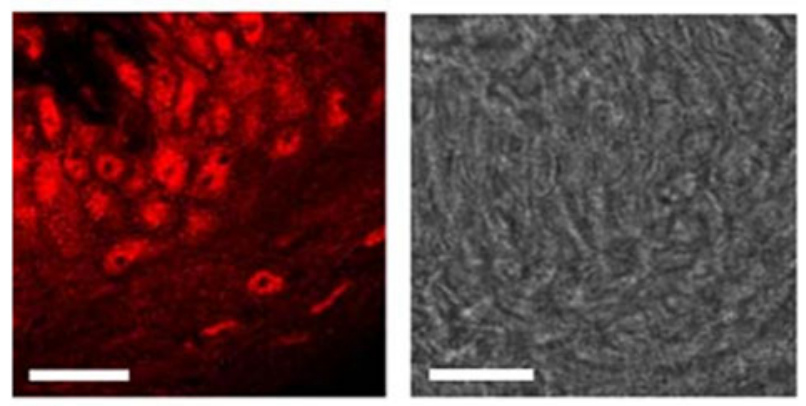

C
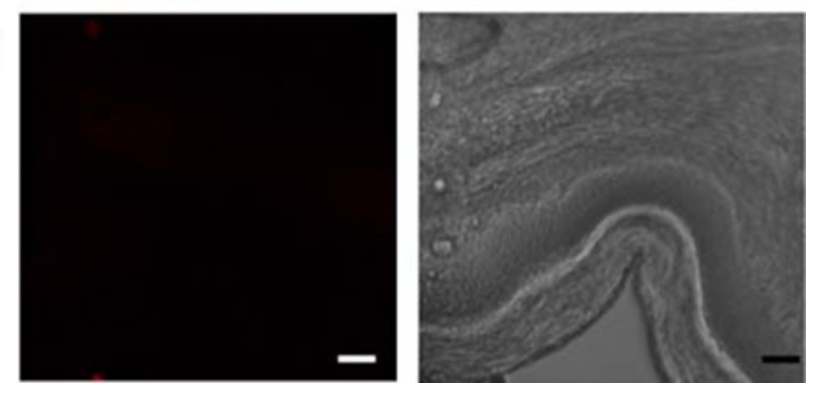

Fig. 2 Immunoreactivity for Kv7.2 within the epidermis of plantar skin. $a, b \mathrm{Kv} 7.2$ (Alomone) immunoreactivity within rat plantar skin with corresponding transmitted light images on the right. $c$ Secondary only antibody. Scale $=40 \mu \mathrm{m}$

Since M-currents are non-inactivating, we sought evidence for an M-current contribution to the outward currents by recording the effects of the M-channel enhancer, retigabine [42] and the M-channel blocker XE991 [44] on the current generated by the slow (25 s) voltage ramp (Fig. 5). Retigabine produced a small increase in mean outward current at depolarized potentials such that the average current amplitude measured at $+50 \mathrm{mV}$ was significantly greater than that of the control current or that recorded in the presence of XE991 (Fig. 5, inset). In contrast, mean outward currents recorded in the absence and presence of XE991 were not significantly different.

The variability in current amplitudes between cells might obscure otherwise consistent but small effects of the Mchannel modulators. Therefore, since we used the same schedule of drug applications in each experiment (controlretigabine-XE991), we carried out a within-experiment comparison by measuring the current ratios at $+50 \mathrm{mV}$ retigabine/control, XE991/control and XE991/retigabine and 
Fig. 3 Immunoreactivity to Kv7.2 channel in rat keratinocytes observed with two different antibodies and after differing times in culture. Fluorescent images to the left, transmitted light images to the right. $a$ Day 3 in culture; $b$ day $5 ; c$ day $10 ; d$ day 3 with secondary antibody only. Scale bar $=20 \mu \mathrm{M}$
Kv7.2 (Abcam)

Kv7.2 (Neuromab)

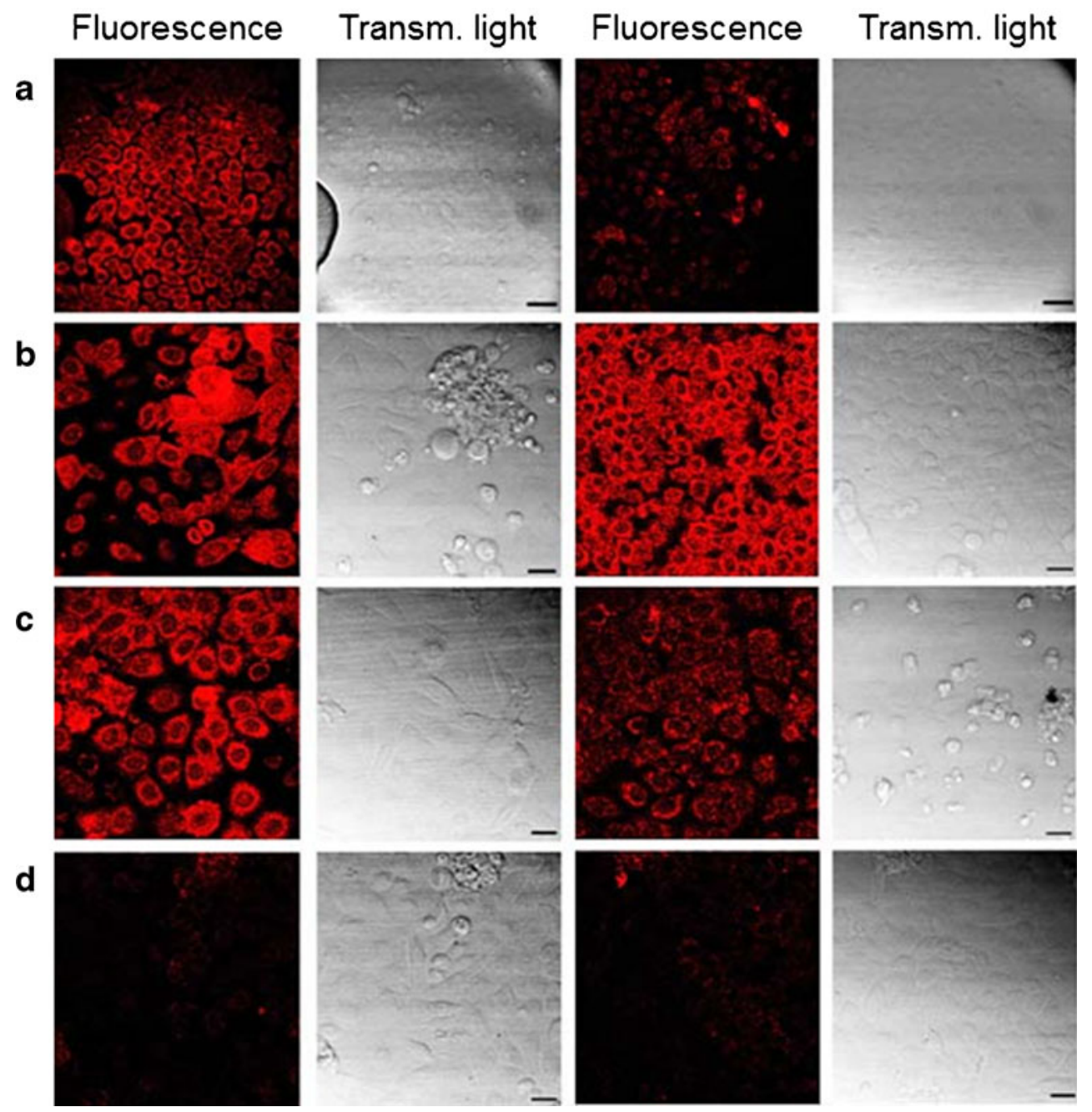

assessing whether their means differed significantly from a null-hypothesis ratio of 1.0 (Table 1). The ratios retigabine/control and XE991/retigabine were significantly different from unity at $P<0.025$ and $P<0.0025$, respectively; that for the ratio XE991/control was marginally outside the $5 \%$ significance level at $P=0.052$. Thus, it would seem likely that functional M-channels (presumably containing Kv7.2 subunits) are present in these keratinocyte membranes, contributing perhaps a quarter of the outward current at positive potentials, and that this current is enhanced $20 \%$ in the presence of retigabine.

\section{Membrane potential}

Several attempts were made to record the effects of Mchannel modulators on the resting membrane potential of the cultured keratinocytes. In most $(5+)$ cells successfully patched, the apparent resting potential was regarded as too positive $(\leq-25 \mathrm{mV})$ and/or too unstable, and recordings aborted or rejected. However, one cell showed a good and relatively stable resting potential $(\sim-75 \mathrm{mV}$; Fig. 6$)$. In this cell, retigabine $(10 \mu \mathrm{M})$ produced a clear hyperpolarization of $\sim 3 \mathrm{mV}$, which was partly reversed on adding $3 \mathrm{mM}$ XE991 and fully recovered on washing. This accords with the effect of retigabine on nerve cells, in which it produces a resting hyperpolarization by shifting the M-channel activation curve so that channels now open at negative potentials where they would normally be closed [42].

\section{ATP release}

To assess the maximum ATP-releasing capacity of cultured keratinocytes, we applied $50 \mu \mathrm{l} \mathrm{NaOH}$ to a series of keratinocyte cultures for $10 \mathrm{~min}$ to give a final bath concentration of $4 \%$ [30]. This increased the ATP concentration in the surrounding medium by about 10 -fold over that recorded on simply adding an aliquot of Krebs' solution, from a mean of $34.6 \pm 5.2 \mathrm{nM}(n=5)$ to $420 \pm 49.5 \mathrm{nM}(n=6)$ (Fig. $7 \mathrm{a})$.

To provide a more physiological stimulus for ATP release, we used the TRPV3 agonist carvacrol [46]. TRPV3 is 
a

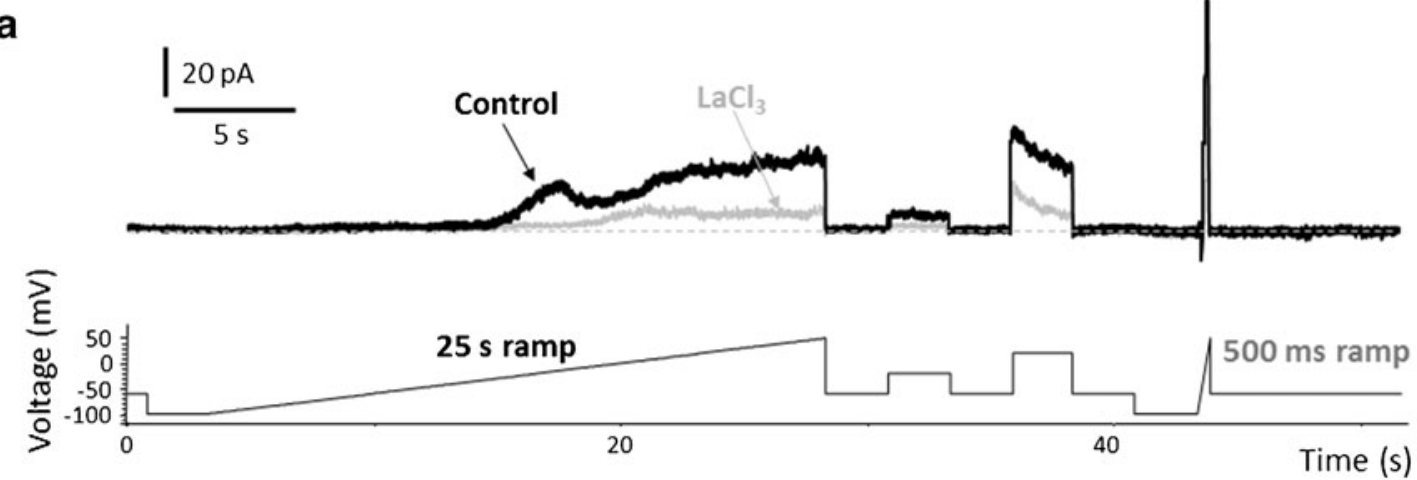

b

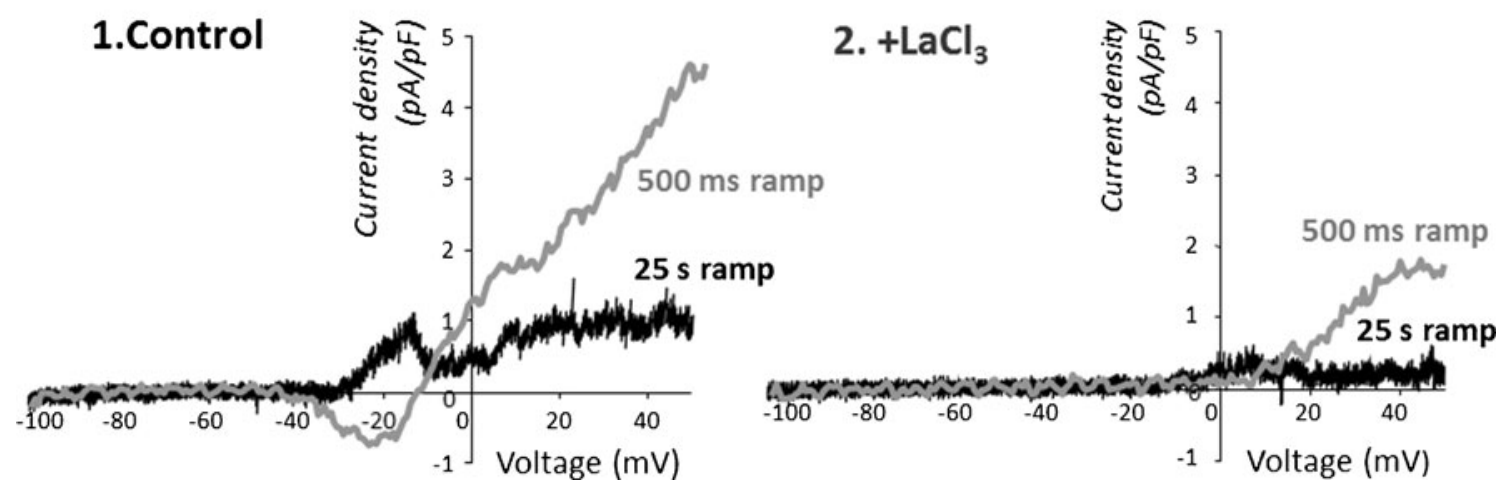

Fig. 4 Membrane currents recorded from an isolated cultured rat keratinocyte. a Voltage and current protocol (upper trace current, lower trace voltage). The cell was held at $-60 \mathrm{mV}$, prepulsed to $-100 \mathrm{mV}$ and then commanded to $+50 \mathrm{mV}$ with a 25 -s voltage ramp. After returning to $-60 \mathrm{mV}$, two $3-\mathrm{s}$ commands to -20 and $+20 \mathrm{mV}$ were applied. Finally, the voltage-ramp procedure was re-applied but at a faster speed
(500 ms). Currents obtained before (black) and after (grey) adding $100 \mu \mathrm{M} \mathrm{LaCl}_{3}$ are shown. The zero current level in the upper (current) trace is indicated by the dashed line. $\mathbf{b}$ Current-voltage relations for $500 \mathrm{~ms}$ (grey) and $25 \mathrm{~s}$ (black) ramps (1) before and (2) after adding $\mathrm{LaCl}_{3}$. Currents were leak-subtracted by subtracting extrapolated linear currents from -100 to $-60 \mathrm{mV}$. Current scale $\mathrm{pA} / \mathrm{pF}$
Fig. 5 Superimposed averaged mean currents $(\mathrm{pA} / \mathrm{pF})$ generated by $25 \mathrm{~s}$ voltage ramps from -100 to $+50 \mathrm{mV}$ in 9 keratinocytes exposed sequentially to Krebs' solution (control, black), $10 \mu \mathrm{M}$ retigabine (amber) and $10 \mu \mathrm{M}$ XE991 (violet). $100 \mu \mathrm{M} \mathrm{LaCl}_{2}$ was subsequently added to 7 of the same 9 cells (brown). Currents were leak-subtracted by subtracting extrapolated linear currents from -100 to $-60 \mathrm{mV}$. Inset means \pm SEMs of current amplitudes at $+50 \mathrm{mV}$. $C$ control, $R$ retigabine, $X$ XE991. Means \pm SEMs (pA/pF) were: control, $1.06 \pm 0.23(n=9)$; retigabine, $1.35 \pm 0.33(n=9)$; XE991, $0.94 \pm$ $0.33(n=9) ; \mathrm{La}^{3+}, 0.40 \pm 0.26$ $(n=7)$. For the bracketed columns, $P$ values (two-tailed $t$ test) were: $*<0.05 ; * *<0.03$
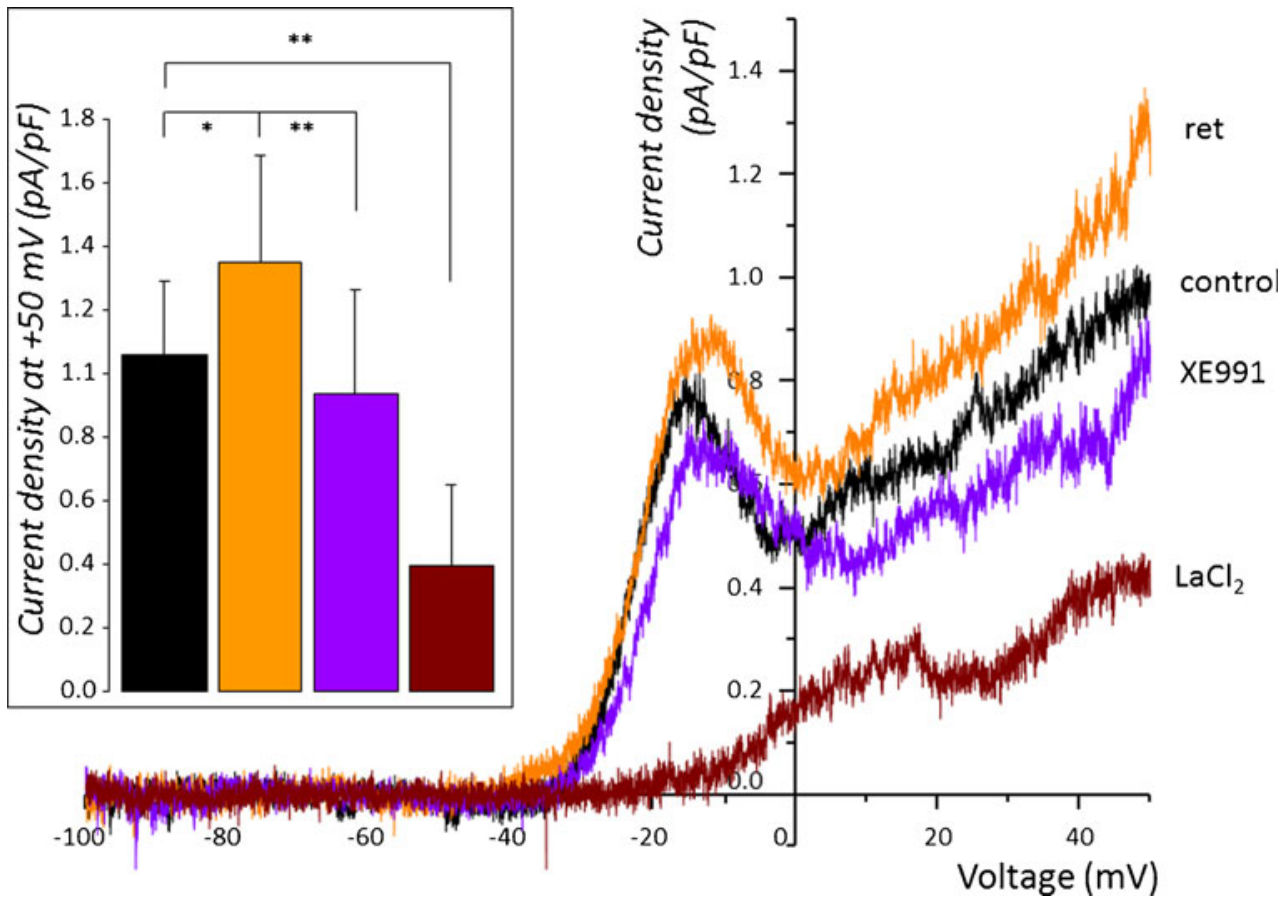
Table 1 Within-experiment measurements of current ratios at $+50 \mathrm{mV}$ from the experiments illustrated in Fig. 6

\begin{tabular}{llll}
\hline & $\begin{array}{l}\text { Retigabine/ } \\
\text { control }\end{array}$ & $\begin{array}{l}\text { XE991/ } \\
\text { control }\end{array}$ & $\begin{array}{l}\text { XE991/ } \\
\text { retigabine }\end{array}$ \\
\hline Mean ratio & 1.208 & 0.730 & 0.583 \\
SEM & 0.0896 & 0.147 & 0.107 \\
$N$ & 9 & 9 & 9 \\
$P$ (difference from 1.0, one tail) & 0.024 & 0.052 & 0.0022 \\
\hline
\end{tabular}

abundantly expressed in keratinocytes [25, 31], and its activation readily induces ATP release [26]. As shown in Fig. $7 \mathrm{~b}, 1 \mathrm{mM}$ carvacrol for $10 \mathrm{~min}$ produced a consistent and significant $(P<0.01)$ increase in ATP release of $>2$-fold over the 10-min exposure period, from $30.4 \pm 3.5 \mathrm{nM}(n=4)$ with Krebs' solution to $70.9 \pm 3.5 \mathrm{nM}(n=4)$.

Addition of the M-channel enhancer retigabine ( $3 \mu \mathrm{M}$ final bath concentration) to the carvacrol solution led to a further 3-fold increase in the amount of ATP released by carvacrol, from $191 \pm 31.8 \mathrm{nM}(n=6)$ to $616 \pm 116 \mathrm{nM}(n=5)$ (Fig $7 \mathrm{c})$. Ten micromolars retigabine produced a similar effect (Fig. 7d). This latter effect was annulled by prior addition of the M-channel blocking agent XE991 $(10 \mu \mathrm{M}$; Fig. 7d) so presumably results from activation of Mchannels. Retigabine $(10 \mu \mathrm{M})$ did not affect spontaneous ATP release in the absence of carvacrol ([ATP]: controls $15.2 \pm 5.9 \mathrm{nM}, n=4)$; retigabine $14.3 \pm 7.8 \mathrm{nM}, n=3)$ ), nor did addition of $50 \mu \mathrm{l}$ of the solvent (5\% DMSO) ([ATP]: controls $15.1 \pm 8.6 \mathrm{nM}, n=4$; DMSO $12.0 \pm 3.8 \mathrm{nM}, n=4)$ ). XE991 $(10 \mu \mathrm{M})$ in the absence of retigabine had no significant effect on either the spontaneous release ([ATP]: controls $73.3 \pm 43.7 \mathrm{nM}, n=4)$; XE991 $98.4 \pm 19 \mathrm{nM}, n=3)$ ) or the enhanced release produced by carvacrol ([ATP]: carvacrol 203.3 $\pm 32.9 \mathrm{nM}, n=4$; carvacrol+XE991 $359.8 \pm$ $84.5 \mathrm{nM}, n=4)$.

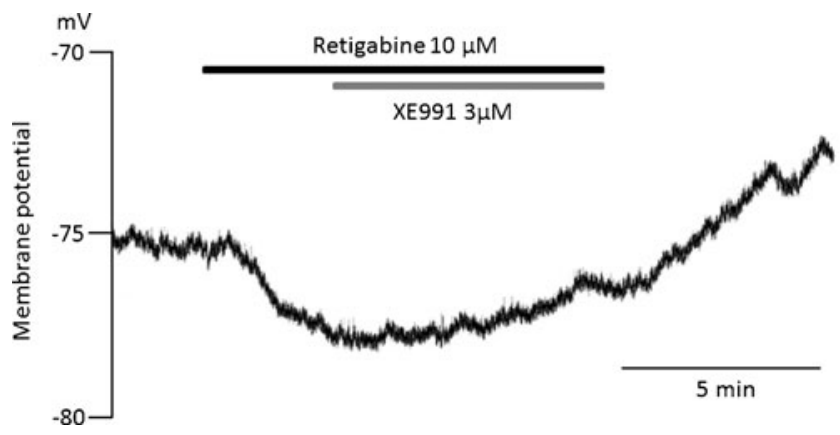

Fig. 6 Retigabine can hyperpolarize a keratinocyte. Membrane potential recording from a cultured keratinocyte. Perforated-patch recording as for Figs. 4 and 5 (see "Methods"). Retigabine $(10 \mu \mathrm{M})$ was added for the duration shown by the upper black bar and supplemented with $3 \mu \mathrm{M}$ XE991 for the period shown by the lower grey bar
Intracellular $\mathrm{Ca}^{2+}$ changes

Carvacrol has been reported to increase intracellular $\left[\mathrm{Ca}^{2+}\right]$ in TRPV3-containing or expressing cells [46]. Since that increase required extracellular $\mathrm{Ca}^{2+}$, it presumably resulted from entry through the $\mathrm{Ca}^{2+}$-permeable TRPV3 channels [45]. In accordance with this, carvacrol increased intracellular $\left[\mathrm{Ca}^{2+}\right]$ in cultured keratinocytes as measured from the 350:380 fluorescence ratio in Fura-2 loaded cells (Fig. 8). Fura-2 signals across different keratinocytes were highly variable, but signals with repeated carvacrol applications to the same keratinocyte were reasonably consistent, albeit with some desensitization as previously reported [46]. Hence, to test whether retigabine affected the $\mathrm{Ca}^{2+}$ signal, we applied carvacrol twice to the same cell then measured the ratio of the second to first responses (R2/R1) on adding either Krebs' solution or $10 \mu \mathrm{M}$ retigabine $5 \mathrm{~min}$ before the second response (Fig. 8a). As shown in Fig. 8b, the second response was smaller on average on adding Krebs solution $(\mathrm{R} 2 / \mathrm{R} 1=0.73 \pm 0.10, n=33)$ but was consistently increased after adding $10 \mu \mathrm{M}$ retigabine (R2/R1 $=1.18 \pm 0.04, n=24)$; the difference between retigabine and Krebs' solution was highly significant $(P<0.01)$. Retigabine itself did not produce any consistent change in resting $\left[\mathrm{Ca}^{2+}\right]$.

\section{Discussion}

The main points emerging from these experiments are that the M-channel Kv7.2 subunit protein is consistently expressed in rat skin epidermal keratinocytes and that these cells also possess functional (or potentially functional) membrane M-channels. Antibodies to Kv7.2 were selected as most helpful in seeking the presence of M-channel proteins because this subunit is not only a component of the heteromeric Kv7.2/7.3 M-channel observed in peripheral neurons $[17,44]$ (and indeed is essential for their functional expression [33]) but also because Kv7.2 subunits can form functional M-channels in the absence of other subunits [37-39]. Using Kv7.2 antibodies, we found a strong band of immunoreactivity in the keratinocytes in the epidermis and around hair follicles in intact rat skin and in keratinocytes from early postnatal rat skin when cultured for a few days in vitro. This is likely to be due to specific staining of Kv7.2 protein since (a) it was replicated by three antibodies directed at different epitopes and (b) where tested (supplementary Fig. S1), it was prevented by the subunitspecific epitope peptide.

Our primary evidence for functionality (or at least, potential functionality) of the Kv7.2 protein as a subunit of the M-channel rests on the effects of the selective M-channel enhancer retigabine. This drug (a) produced a small ( $20 \%)$ but consistent increase in outward membrane current, (b) 


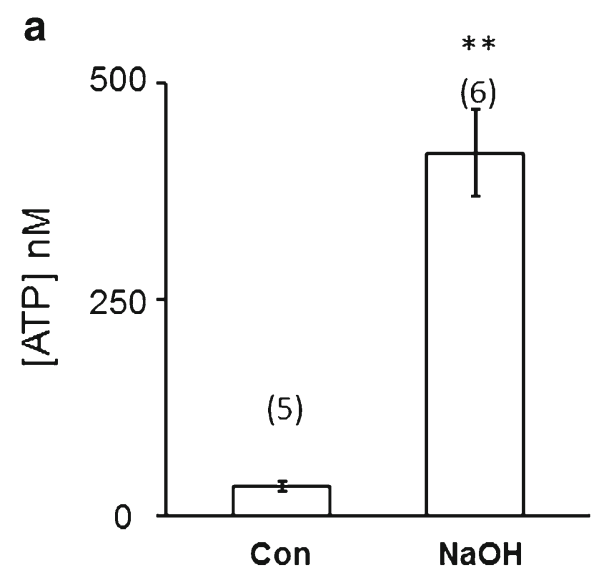

b
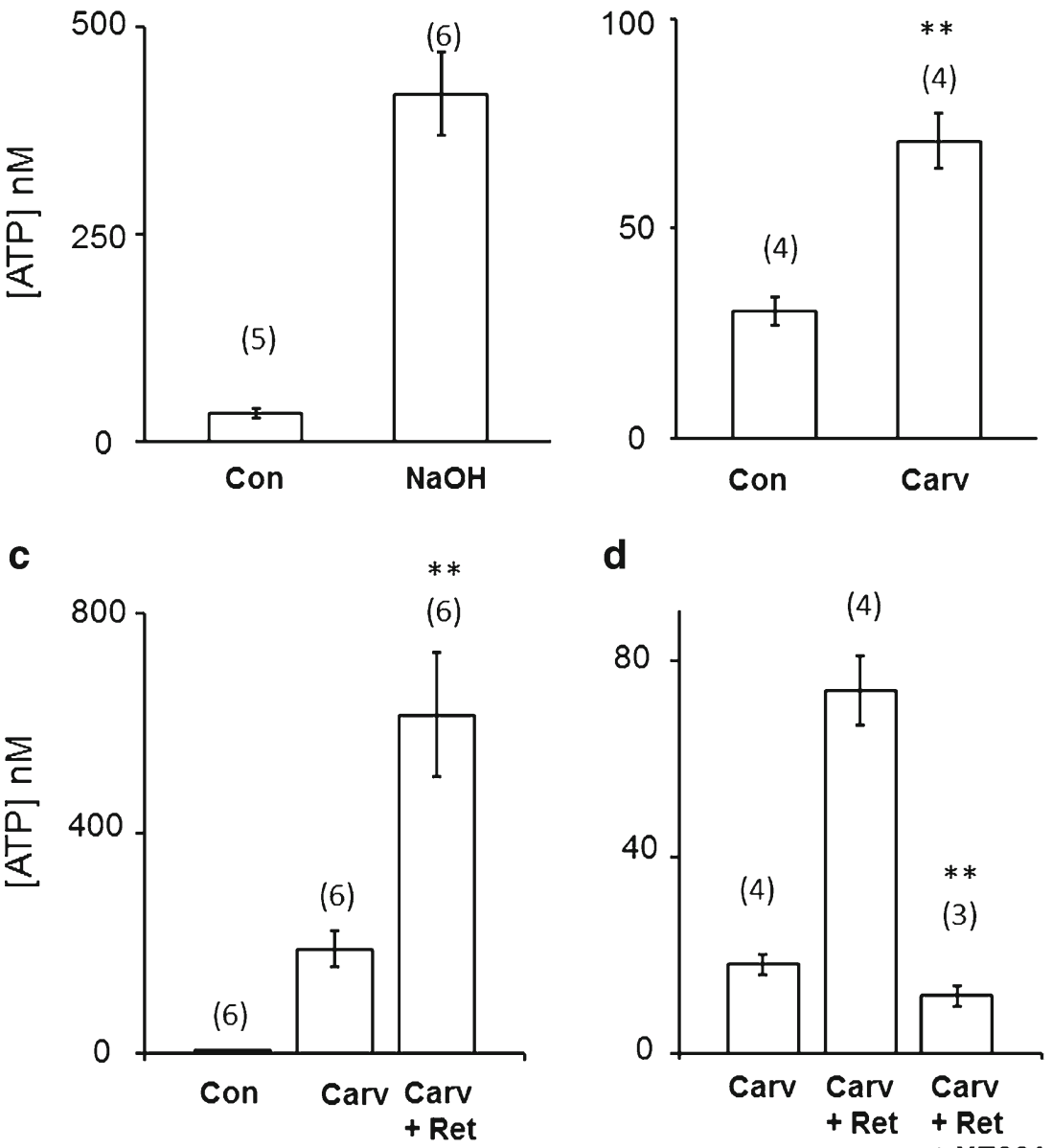

d

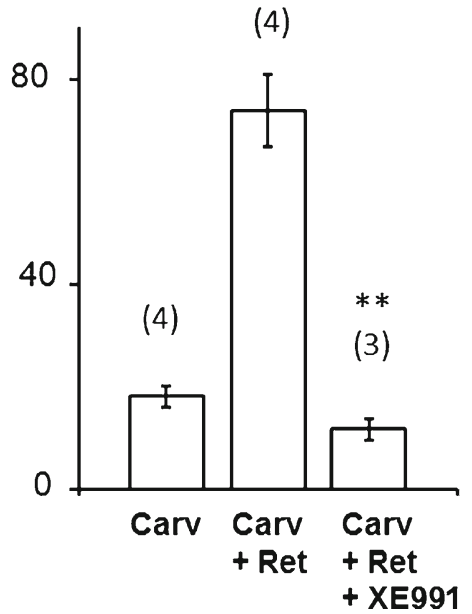

Fig. 7 Stimulated ATP release from cultured keratinocytes $(\mathbf{a}, \mathbf{b})$ and effects of retigabine thereon $(\mathbf{c}, \mathbf{d})$. Data in $\mathbf{a}-\mathbf{d}$ are from four separate keratinocyte cultures. Ordinates show concentrations of ATP ([ATP], in nanomolars) in $50 \mu \mathrm{l}$ aliquots of Krebs' solution overlying the keratinocyte cultures (total bath volume $500 \mu \mathrm{l}$ ) determined using the luciferase assay (see "Methods"). Aliquots were taken $10 \mathrm{~min}$ after adding $50 \mu \mathrm{l}$ Krebs' solution to the keratinocyte chambers (controls, Con) or 10 min after adding: a $\mathrm{NaOH}$ (final bath concentration $4 \%$ ), b

hyperpolarized a keratinocyte with a high $(-75 \mathrm{mV})$ resting potential, (c) augmented the release of ATP by the TRPV3 agonist carvacrol and (d) enhanced the increase in intracellular $\mathrm{Ca}^{2+}$ produced by carvacrol. The enhanced release of ATP by retigabine was suppressed by the M-channel blocking drug XE991, showing that this effect at least was unambiguously due to the action of retigabine on $\mathrm{M}$ channels. On the other hand, XE991 alone did not produce a clearly significant $(P=0.052)$ reduction in voltageactivated membrane current (which was dominated by $\mathrm{Ca}^{+}$-activated outward currents) and did not significantly affect either the stimulated or resting release of ATP. This may suggest that, in these cultured cells at least, the density of functional M-channels is rather low compared with that in peripheral neurons and/or that very few of these voltage- carvacrol (Carv, final bath concentration $1 \mathrm{mM})$, c $1 \mathrm{mM}$ carvacrol alone or $1 \mathrm{mM}$ carvacrol with $10 \mu \mathrm{M}$ added retigabine (Ret) and d $1 \mathrm{mM}$ carvacrol, $1 \mathrm{mM}$ carvacrol with $10 \mu \mathrm{M}$ retigabine and $1 \mathrm{mM}$ carvacrol $+10 \mu \mathrm{M}$ retigabine $2 \mathrm{~min}$ after pre-addition of $10 \mu \mathrm{M}$ XE991. Numbers in brackets are numbers of culture dishes sampled from each culture; $* * P<0.01$ (difference from controls or, in $\mathbf{d}$, between carvacrol+retigabine with and without added XE991)

gated channels are activated at the membrane potential of these cells and only carry appreciable current when their activation is enhanced by retigabine. On the other hand, the channels might well be present at a higher density in adult keratinocytes than in cultured immature keratinocytes and then might form a more substantial component of resting membrane current, since Kv7.2 immunoreactivity was appreciably stronger in adult rat skin keratinocytes than in the cultured cells and indeed comparable to that in neighbouring nerve fibres (Supplementary Fig. S2).

TRPV3 channels are $\mathrm{Ca}^{2+}$-permeable [45], and as reported previously for other TRPV3-expressing cells [46], their activation by carvacrol increased intracellular $\mathrm{Ca}^{2+}$ in our cultured keratinocytes (Fig. 8). Since raising intracellular $\mathrm{Ca}^{2+}$ in keratinocytes can release ATP [23], as in some 
a

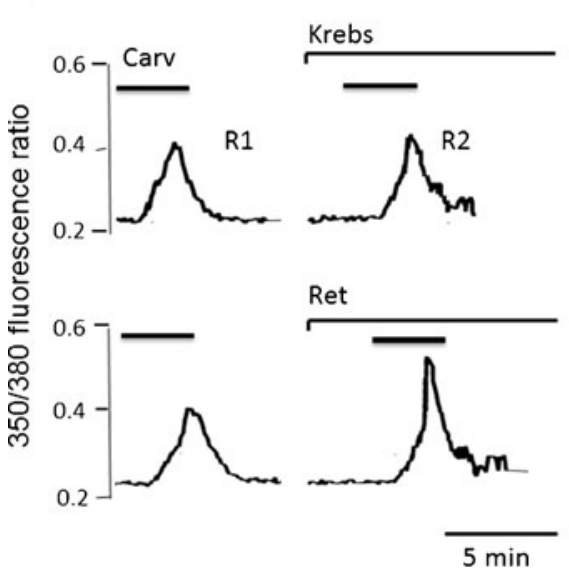

b

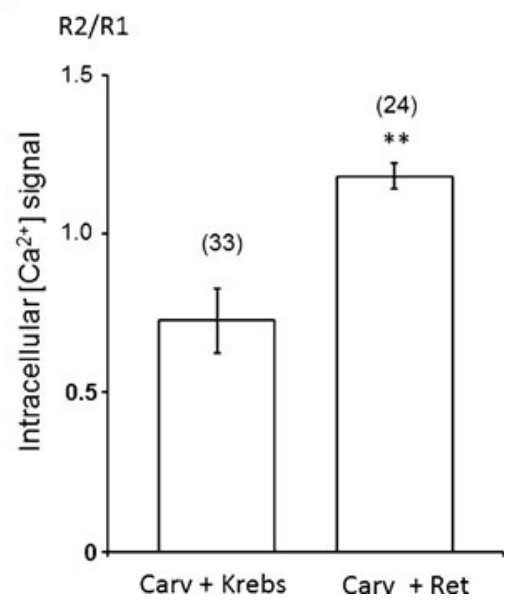

Fig. 8 Retigabine enhances the increase in intracellular $\left[\mathrm{Ca}^{2+}\right]$ in cultured keratinocytes produced by carvacrol. a Representative $\mathrm{Ca}^{2+}$ signals, measured as increases in the 350:380-nm fluorescence signal in Fura-2 preloaded cells and recorded from two keratinocytes following two applications to each of $1 \mathrm{mM}$ carvacrol for $3 \mathrm{~min}$. The top trace shows representative responses to two successive applications of carvacrol. In the lower trace, the second carvacrol application was preceded by the addition of retigabine (Ret: bath concentration $10 \mu \mathrm{M})$. b The mean ratio of the second-to-first responses (R2/R1) following addition of Krebs' solution (Carv+Krebs) or retigabine (Carv+Ret) before the second response. Bars are SEM, number of cells in brackets. The asterisk (**) indicated that the R2/R1 ratio is significantly greater when $\mathrm{R} 2$ was preceded by retigabine than when it was not $(P<0.01)$ other cells (e.g. [6, 9, 23]), it seems reasonable to suppose that the rise in $\left[\mathrm{Ca}^{2+}\right]_{\text {in }}$ is primarily responsible for the release of ATP by carvacrol, though other mechanisms for release are possible $[2,5]$. Retigabine produced a significant increase in the carvacrol-induced rise in $\left[\mathrm{Ca}^{2+}\right]_{\text {in }}$ though whether this is quantitatively sufficient to explain the increased ATP release in uncertain.

Likewise, the mechanism whereby increasing M-channel activity with retigabine increases the carvacrol-induced $\mathrm{Ca}^{2+}$ transient and ATP release is, as yet, equally unclear. One possibility is that an M-current-induced hyperpolarization increases the driving force for $\mathrm{Ca}^{2+}$ entry through the TRPV3 channels. The hyperpolarization at rest potential was rather small $(\sim 3 \mathrm{mV}$; Fig. 6) but since the channels are voltage-sensitive, the retigabine-enhanced channels may have a much more significant effect in reducing the TRPV3induced depolarization (essentially clamping the membrane potential near to the resting potential) and hence increasing the $\mathrm{Ca}^{2+}$ driving force at the peak of TRPV3 activation. Additionally, the activated M-channel might have some more direct effect on the TRPV3 channel to enhance its activity or sensitivity to carvacrol. Thus, Kv7.2 and TRPV1 have been reported to co-precipitate when co-expressed in HEK 293 cells, though in this case without effect of retigabine on the action of the TRPV1 ligand, capsaicin [47]. Further tests for Kv7.2-TRPV3 interaction might be worthwhile.

Physiologically, TRPV3 (and TRPV4) channels in keratinocytes are suggested to mediate keratinocyte thermosensation, probably through the release of ATP and activation of subjacent sensory fibres [25]. Thus, in cocultures of dorsal root ganglion neurons with keratinocytes, the response of the neurons to an applied heat ramp has been shown to result from activation of the keratinocyte TRPV3 channels and the release of ATP onto the adjacent neurons, rather than to a direct effect on the neurons [26]. Assuming that retigabine has a comparable effect on the response of keratinocyte TRPV3 channels to heat as that to carvacrol observed in the present study, retigabine would be expected enhance skin thermosensation. Thus, the fact that retigabine exerted the opposite (suppressant) effect on thermally-induced skin peripheral afferent discharges in situ [34] would seem to rule out the possibility that the latter effects were mediated indirectly via the keratinocytes. On the other hand, the effects of retigabine on keratinocyte responses might imply some limitation to the prospective utility of retigabine in suppressing pathological nociceptive activity [36].

Apart from thermal sensation, keratinocyte TRPV3 channels and local ATP release may be involved in other aspects of skin function including vasodilator responses and the regulation of skin structure and permeability [12, 25]. For example, openers of some other $\mathrm{K}^{+}$channels have been reported to accelerate epidermal barrier recovery after barrier disruption [13]. Keratinocytes also possess Gq-coupled receptors such as purinergic $\mathrm{P} 2 \mathrm{Y}$ receptors [14] and bradykinin B2 receptors [41], which would be expected to modulate M-channel activity [10]. Thus, the presence of Mchannels and their effects noted in the present paper may have rather broad implications for skin biology and possibly some therapeutic implications for wound healing 
Acknowledgments This work was part-supported by grant G0500194 from the U.K. Medical Research Council. Retigabine was supplied by Neurosearch (Ballerup, Denmark) via EU grant LSHM-CT-2004503038 .

Open Access This article is distributed under the terms of the Creative Commons Attribution License which permits any use, distribution, and reproduction in any medium, provided the original author(s) and the source are credited.

\section{References}

1. Atoyan R, Shander D, Botchkareva NV (2009) Non-neuronal expression of transient receptor potential type A1 (TRPA1) in human skin. J Invest Dermatol 129:2312-2315

2. Azorin N, Raoux M, Rodat-Despoix L, Merrot T, Delmas P, Crest M (2011) ATP signalling is crucial for the response of human keratinocytes to mechanical stimulation by hypo-osmotic shock. Exp Dermatol 20:401-407

3. Beck B, Lehen'kyi V, Roudbaraki M, Flourakis M, Charveron M, Bordat P, Polakowska R, Prevarskaya N, Skryma R (2008) TRPC channels determine human keratinocyte differentiation: new insight into basal cell carcinoma. Cell Calcium 43:492-505

4. Bíró T, Kovács L (2009) An "ice-cold” TR(i)P to skin biology: the role of TRPA1 in human epidermal keratinocytes. J Invest Dermatol 129:2096-2099

5. Bodin P, Burnstock G (2001) Purinergic signalling: ATP release. Neurochem Res 126:959-969

6. Boudreault F, Grygorczyk R (2004) Cell swelling-induced ATP release is tightly dependent on intracellular calcium elevations. $\mathrm{J}$ Physiol 561:499-513

7. Brouard M, Casado M, Djelidi S, Barrandon Y, Farman N (1999) Epithelial sodium channel in human epidermal keratinocytes: expression of its subunits and relation to sodium transport and differentiation. J Cell Sci 112(Pt 19):3343-3352

8. Cao C, Healey S, Amaral A, Lee-Couture A, Wan S, Kouttab N, Chu W, Wan Y (2007) ATP-sensitive potassium channel: a novel target for protection against UV-induced human skin cell damage. J Cell Physiol 212:252-263

9. Coco S, Calegari F, Pravettoni E, Pozzi D, Taverna E, Rosa P, Matteoli M, Verderio C (2003) Storage and release of ATP from astrocytes in culture. J Biol Chem 278:1354-1362

10. Delmas P, Brown DA (2005) Pathways modulating neural KCNQ/ M (Kv7) potassium channels. Nat Rev Neurosci 6:850-862

11. Denda M, Fuziwara S, Hibino T (2006) Expression of voltagegated calcium channel subunit $\mathrm{aC} 1$ in epidermal keratinocytes and effects of agonist and antagonists of the channel on skin barrier homeostasis. Exp Dermatol 15:455-460

12. Denda M, Nakatani M, Ikeyama K, Tsutsumi M, Denda S (2007) Epidermal keratinocytes as the forefront of the sensory system. Exp Dermatol 16:157-161

13. Denda M, Tsutsumi M, Inoue K, Crumrine D, Feingold KR, Elias PM (2007) Potassium channel openers accelerate epidermal barrier recovery. Br J Dermatol 157:888-893

14. Dixon CJ, Bowler WB, Littlewood-Evans A, Dillon JP, Bilbe G, Sharpe GR, Gallagher JA (1999) Regulation of epidermal homeostasis through P2Y2 receptors. Br J Pharmacol 27:1680-1686

15. Dlugosz AA, Glick AB, Tennenbaum T, Weinberg WC, Yuspa SH (1995) Isolation and utilization of epidermal keratinocytes for oncogene research. Methods Enzymol 254:3-20

16. Fatherazi S, Presland RB, Belton CM, Goodwin P, Al-Qutub M, Trbic Z, Macdonald G, Schubert MM, Izutsu KT (2007) Evidence that TRPC4 supports the calcium selective I(CRAC)-like current in human gingival keratinocytes. Pflugers Arch 453:879-889

17. Hadley JK, Passmore GM, Tatulian L, Al-Qatari M, Ye F, Wickenden AD, Brown DA (2003) Stoichiometry of expressed KCNQ2/ KCNQ3 channels and subunit composition of native ganglionic Mchannels deduced from block by tetraethylammonium (TEA). J Neurosci 23:5012-5019

18. Inoue K, Koizumi S, Fuziwara S, Denda S, Inoue K, Denda M (2002) Functional vanilloid receptors in cultured normal human epidermal keratinocytes. Biochem Biophys Res Commun 291:124-129

19. Ivanchenko E, Markwardt F (2005) Characterization of largeconductance $\mathrm{Ca} 2+$-dependent and -independent $\mathrm{K}+$ channels in HaCaT keratinocytes. Skin Pharmacol Physiol 18:115-122

20. Kang D, Kim SH, Hwang EM, Kwon OS, Yang HY, Kim ES, Choi TH, Park JY, Hong SG, Han J (2007) Expression of thermosensitive two-pore domain $\mathrm{K}+$ channels in human keratinocytes cell line HaCaT cells. Exp Dermatol 16:1016-1022

21. Koegel H, Alzheimer C (2001) Expression and biological significance of $\mathrm{Ca} 2+$-activated ion channels in human keratinocytes. FASEB J 15:145-154

22. Koegel H, Kaesler S, Burgstahler R, Werner S, Alzheimer C (2003) Unexpected down-regulation of the hIK1 $\mathrm{Ca}^{2+}$-activated channel by its opener 1-ethyl-2-benzimidazolinone in $\mathrm{HaCaT}$ keratinocytes. Inverse effects on cell growth and proliferation. J Biol Chem 278:3323-3330

23. Koizumi S, Fujishita K, Inoue K, Shigemoto-Mogami Y, Tsuda M, Inoue $\mathrm{K}$ (2004) $\mathrm{Ca} 2+$ waves in keratinocytes are transmitted to sensory neurons: the involvement of extracellular ATP and P2Y2 receptor activation. Biochem J 380:329-338

24. Kolly C, Suter MM, Muller EJ (2005) Proliferation, cell cycle exit, and onset of terminal differentiation in cultured keratinocytes: preprogrammed pathways in control of C-Myc and Notch1 prevail over extracellular calcium signals. J Invest Dermatol 124:1014-1025

25. Lee H, Caterina MJ (2005) TRPV channels as thermosensory receptors in epithelial cells. Pflugers Arch 451:160-167

26. Mandadi S, Sokabe T, Shibasaki K, Katanosaka K, Mizuno A, Moqrich A, Patapoutian A, Fukumi-Tominaga T, Mizumura K, Tominaga M (2009) TRPV3 in keratinocytes transmits temperature information to sensory neurons via ATP. Pflugers Arch 458:1093-1102

27. Mauro TM, Dixon DB, Komuves L, Hanley K, Pappone PA (1997) Keratinocyte $\mathrm{K}^{1}$ channels mediate $\mathrm{Ca} 2^{1}$-induced differentiation. J Invest Dermatol 108:864-870

28. Mauro MT, Pappone AP, Isseroff RR (1990) Extracellular calcium affects the membrane currents of cultured human keratinocytes. J Cell Physiol 143:13-20

29. Mihara H, Boudaka A, Sugiyama T, Moriyama Y, Tominaga M (2011) Transient receptor potential vanilloid 4 (TRPV4)-dependent calcium influx and ATP release in mouse oesophageal keratinocytes. J Physiol 589:3471-3482

30. Mizumoto N, Mummert ME, Shalhevet D, Takashima A (2003) Keratinocyte ATP release assay for testing skin-irritating potentials of structurally diverse chemicals. J Invest Dermatol 121:1066-1072

31. Moqrich A, Hwang SW, Earley TJ, Petrus MJ, Murray AN, Spencer KSR, Andahazy M, Story GM, Patapoutian A (2005) Impaired thermosensation in mice lacking TRPV3, a heat and camphor sensor in the skin. Science 307:1468-1472

32. Nilius B, Owsianik G, Voets T, Peters JA (2007) Transient receptor potential cation channels in disease. Physiol Rev 87:165-217

33. Passmore GM, Robbins J, Abogadie FC, Brown DA (2006) The KCNQ2 (Kv7.2) gene is required for functional M-channels in embryonic mouse superior cervical ganglion (SCG) neurones. Proc Physiol Soc 3:C106

34. Passmore GM, Reilly JM, Thakur M, Keasberry VN, Marsh SJ, Dickenson AH, Brown DA (2012) Functional significance of Mtype potassium channels in nociceptive cutaneous sensory endings. Front Mol Neurosci 5:63. doi:10.3389/fnmol.2012.00063 
35. Peier AM, Reeve AJ, Andersson DA, Moqrich A, Earley TJ, Hergarden AC, Story GM, Colley S, Hogenesch JB, McIntyre P, Bevan S, Patapoutian A (2002) A heat-sensitive TRP channel expressed in keratinocytes. Science 296:2046-2049

36. Rivera-Arconada I, Roza C, Lopez-Garcia JA (2009) Enhancing m currents: a way out for neuropathic pain? Front Mol Neurosci 2:10. doi:10.3389/neuro.02.010.2009

37. Schwarz JR, Glassmeier G, Cooper E, Kao T, Nodera H, Tabuena D, Kaji R, Bostock H (2006) KCNQ channels mediate IKs, a slow $\mathrm{K}+$ current regulating excitability in the node of Ranvier. J Physiol $573: 17-34$

38. Selyanko AA, Hadley JK, Wood IC, Abogadie FC, Jentsch TJ, Brown DA (2000) Inhibition of KCNQ1-4 potassium channels expressed in mammalian cells via M1 muscarinic acetylcholine receptors. J Physiol 522:349-355

39. Shapiro MS, Roche JP, Kaftan EJ, Cruzblanca H, Mackie K, Hille B (2000) Reconstitution of muscarinic modulation of the KCNQ2/ KCNQ3 $\mathrm{K}(+)$ channels that underlie the neuronal $\mathrm{M}$ current. J Neurosci 20:1710-1721

40. Shieh DB, Yang SR, Shi XY, Wu YN, Wu SN (2005) Properties of $\mathrm{BK}(\mathrm{Ca})$ channels in oral keratinocytes. J Dent Res 84:468-473

41. Talwar HS, Fisher GJ, Voorhees JJ (1990) Bradykinin induces phosphoinositide turnover, 1,2-diglyceride formation, and growth in cultured adult human keratinocytes. J Invest Dermatol 95:705-710

42. Tatulian L, Delmas P, Abogadie FC, Brown DA (2001) Activation of expressed KCNQ potassium currents and native neuronal M- type potassium currents by the anti-convulsant drug retigabine. $\mathrm{J}$ Neurosci 21:5535-5545

43. Telezhkin V, Thomas AM, Harmer SC, Tinker A, Brown DA (2013) A basic residue in the proximal C-terminus is necessary for efficient activation of the M-channel subunit Kv7.2 by PI(4,5)P(2). Pflugers Arch. doi:10.007/s0042-012-1199-3

44. Wang HS, Pan Z, Shi W, Brown BS, Wymore RS, Cohen IS, Dixon JE, McKinnon D (1998) KCNQ2 and KCNQ3 potassium channel subunits: molecular correlates of the M-channel. Science 282:1890-1893

45. Xu H, Ramsey IS, Kotecha SA, Moran MM, Chong JA, Lawson D, Ge P, Lilly J, Silos-Santiago I, Xie Y, DiStefano PS, Curtis R, Clapham DE (2002) TRPV3 is a calcium-permeable temperaturesensitive cation channel. Nature 418:181-186

46. Xu H, Delling M, Jun JC, Clapham DE (2006) Oregano, thyme and clove-derived flavors and skin sensitizers activate specific TRP channels. Nat Neurosci 9:628-635

47. Zhang XF, Han P, Neelands TR, McGaraughty S, Honore P, Surowy CS, Zhang D (2011) Coexpression and activation of TRPV1 suppress the activity of the KCNQ2/3 channel. J Gen Physiol 138:341-352

48. Zhao P, Barr TP, Hou Q, Dib-Hajj SD, Black JA, Albrecht PJ, Petersen K, Eisenberg E, Wymer JP, Rice FL, Waxman SG (2008) Voltage-gated sodium channel expression in rat and human epidermal keratinocytes: evidence for a role in pain. Pain 139:90-105 